\title{
Hypoglycaemia secondary to the secretion of pro-insulin like growth factor II by a metastatic neuroendocrine tumour with sarcomatous differentiation
}

\author{
Mia Morgan, Alexandra Nanzer, Cecilia Camacho-Hubner, \\ Gregory A. Kaltsas, John P. Monson
}

Department of Endocrinology, St Bartholomew's Hospital, London EC1A 7BE, UK

\begin{abstract}
A patient presented with frequent episodes of spontaneous hypoglycaemia due to a disseminated neuroendocrine tumour with sarcomatous differentiation, secreting incompletely processed proinsulin-like growth factor II (pro-IGF-II). Although the combination of GH and glucocorticoid therapy initially controlled the hypoglycaemia, there was a later escape necessitating frequent readmissions to hospital. The patient deceased two weeks following her latest admission.
\end{abstract}

Key words: Hypoglycemia, neuroendocrine tumour, IGF-II

\section{INTRODUCTION}

Non-islet-cell tumour-induced hypoglycaemia (NICTH) is a syndrome attributed to the production of an abnormal form of insulin-like growth factor II (IGF-II $)^{1,2}$. This abnormal (big) form of IGF-II is the product of defective processing of pro-IGF-II by the tumour ${ }^{1}$ which is incompletely sequestered in high molecular weight IGF binding protein (IGFBP) complexes and therefore capable of exerting potent insulin-like activity, causing severe hypoglycaemia ${ }^{1,2}$.

The majority of these cases involve elderly patients

Address correspondence and requests for reprints to:

Professor J.P. Monson, Department of Endocrinology,

St. Bartholomew's Hospital, London, EC1A 7BE,

Tel: +44 207601 8343, Fax: +44 207601 8505,

e-mail: J.P.Monson@qmul.ac.uk

Received 28-01-03, Revised 27-02-03, Accepted 11-03-03 for whom the survival period is relatively brief following the onset of hypoglycaemia ${ }^{2}$. The only curative treatment has been surgical intervention, although in relatively few cases this was not a long-term solution due to the often diffuse infiltration of many of the tumours and the advanced age of the patients ${ }^{2,3}$. Therefore, other therapeutic options have been applied, mainly aiming to counteract hypoglycaemia. However, the pharmaceutical manipulation of these patients requires precise knowledge of the underlying pathophysiology and potential pharmaceutic interactions. We present a case and provide a review of the pathophysiology of and therapeutic option for these unusual and largely unmanageable tumours.

\section{CASE REPORT}

A 51-year old lady initially presented with flu- like symptoms that did not respond to conventional treat- 
ment. Two months later she developed intermittent severe right upper quadrant pain and episodes of dizziness without associated loss of consciousness. Clinical examination revealed irregular hepatomegaly, and CT-scanning of the abdomen disclosed multiple soft tissue lesions involving both lobes of the liver, the bowel, the mesentery, the ribs and possibly the right kidney (Figure 1). A liver biopsy showed tumour cells with a moderate amount of eosinophilic cytoplasm and uniform hyperchromatic nuclei. Morphology and histochemistry revealed argentaffin granules and immunohistochemistry was positive for chromo-granin but negative for cytokeratins. In addition, positivity for vimentin suggested sarcomatous differentiation; no tumour markers were measured at that stage. A diagnosis of disseminated neuroendocrine tumour was made and on that basis the patient was given 12 cycles of 5-fluorouracil based chemotherapy and focal radiotherapy to bony lesions with partial symptomatic and tumour response. Eighteen months later the patient presented with a three-week history of episodes of night sweats associated with dizziness. In view of these symptoms and the histological diagnosis of a disseminated neuroendocrine tumour, the long-acting somatostatin analogue lanreotide SR $20 \mathrm{mg}$ every 14 days was prescribed but was discontinued after a month, as her symptoms did not improve. A month later the patient was readmitted following an episode of loss of consciousness associated with sweating and tremor; there was no previous history of diabetes mellitus and the patient was not receiving any medication.

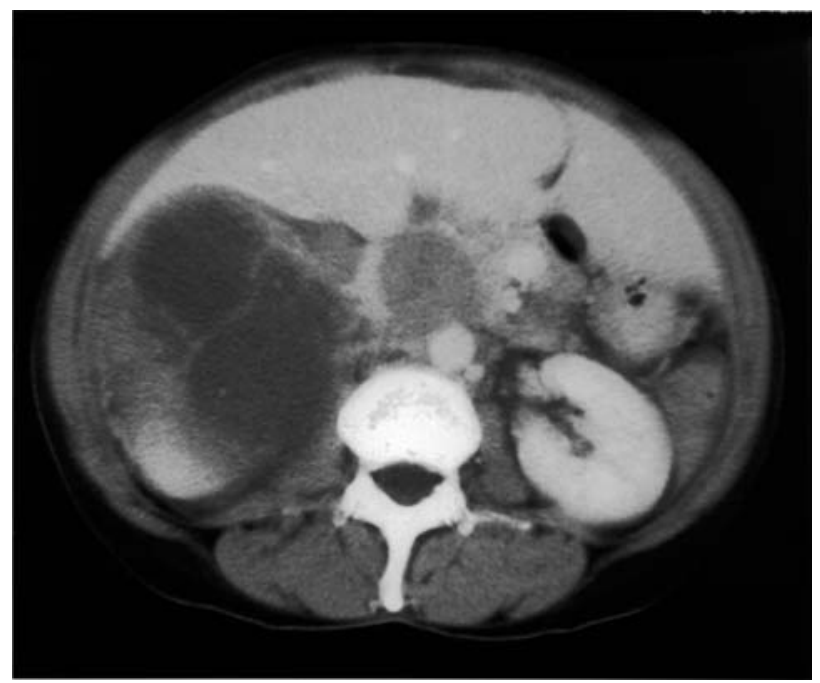

Figure 1. CT of the abdomen demonstrating a large tumor.
Capillary blood glucose was $0.8 \mathrm{mmol} / \mathrm{l}$ and the patient was treated with bolus intravenous $10 \%$ Dextrose infusion with subsequent normalisation of her blood glucose. A provisional diagnosis of endogenous hyperinsulinism, probably secondary to a disseminated insulinoma, was made; serum was taken for measurement of insulin, C-peptide and proinsulin levels and treatment with diazoxide was suggested. Following initial improvement, the patient was found unresponsive, sweaty and tachycardic and a concomitant capillary blood glucose was $0.9 \mathrm{mmol} / \mathrm{L}$. She was resuscitated and thereafter maintained on a $10 \%$ Dextrose infusion and transferred to our Hospital. On clinical examination she was jaundiced, cachetic (body mass index, BMI =16), tachycardic and afebrile. There was evidence of bilateral pleural effusions, irregular hepatomegaly and ascites but no evidence of hepatic decompensation (laboratory investigations are shown in Table 1). As the previously sampled serum insulin levels were found to be undetectable in the presence of hypoglycaemia, a probable diagnosis of a pre-pro IGF-II secreting tumour was made. Review of the histology (Figure 2) was consistent with a neuroendocrine tumour and multiple bony metastases; an ${ }^{111}$ Inpentetreotide scan was not performed. The diagnosis was confirmed by demonstration that pro-IGF-II levels consisted $45 \%$ of total IGFII levels (Reference range 20-28\%) (Figure 3). Serum IGF-I and serum IGFBP3 were subnormal indicating reduced GH se-

Table 1. Routine biochemical investigations at the time of presentation

\begin{tabular}{lcc}
\hline & & Normal values \\
\hline $\mathrm{Na}$ & 118 & $135-145(\mathrm{mmol} / \mathrm{l})$ \\
$\mathrm{K}$ & 4.7 & $3.5-5.1(\mathrm{mmol} / \mathrm{l})$ \\
$\mathrm{Cl}$ & 86 & $98-106(\mathrm{mmol} / \mathrm{l})$ \\
Urea & 13.3 & $2.5-6.4(\mathrm{mmol} / \mathrm{l})$ \\
$\mathrm{Creat}$ & 116 & $58-93(\mathrm{mmol} / \mathrm{l})$ \\
$\mathrm{CCa}$ & 2.4 & $2.15-2.65(\mathrm{mmol} / \mathrm{l})$ \\
Phos & 2.38 & $0.8-1.5(\mathrm{mmol} / \mathrm{l})$ \\
Alb & 26 & $35-56(\mathrm{~g} / \mathrm{l})$ \\
Bili & 170 & $<17(\mathrm{mmol} / \mathrm{l})$ \\
ALP & 222 & $39-117(\mathrm{u} / \mathrm{l})$ \\
ALT & 15 & $<40(\mathrm{u} / \mathrm{l})$ \\
gGT & 47 & $<31(\mathrm{u} / \mathrm{l})$ \\
LDH & 9130 & $70-250(\mathrm{u} / \mathrm{l})$ \\
AST & 187 & $12-39(\mathrm{u} / \mathrm{l})$ \\
\hline
\end{tabular}


cretion and again consistent with a diagnosis of proIGF-II secreting tumour. Treatment with prednisolo- ne $30 \mathrm{mg}$ daily orally, GH $1.3 \mathrm{mg} /$ daily subcutaneously and intravenous antibiotics was initiated with subse-
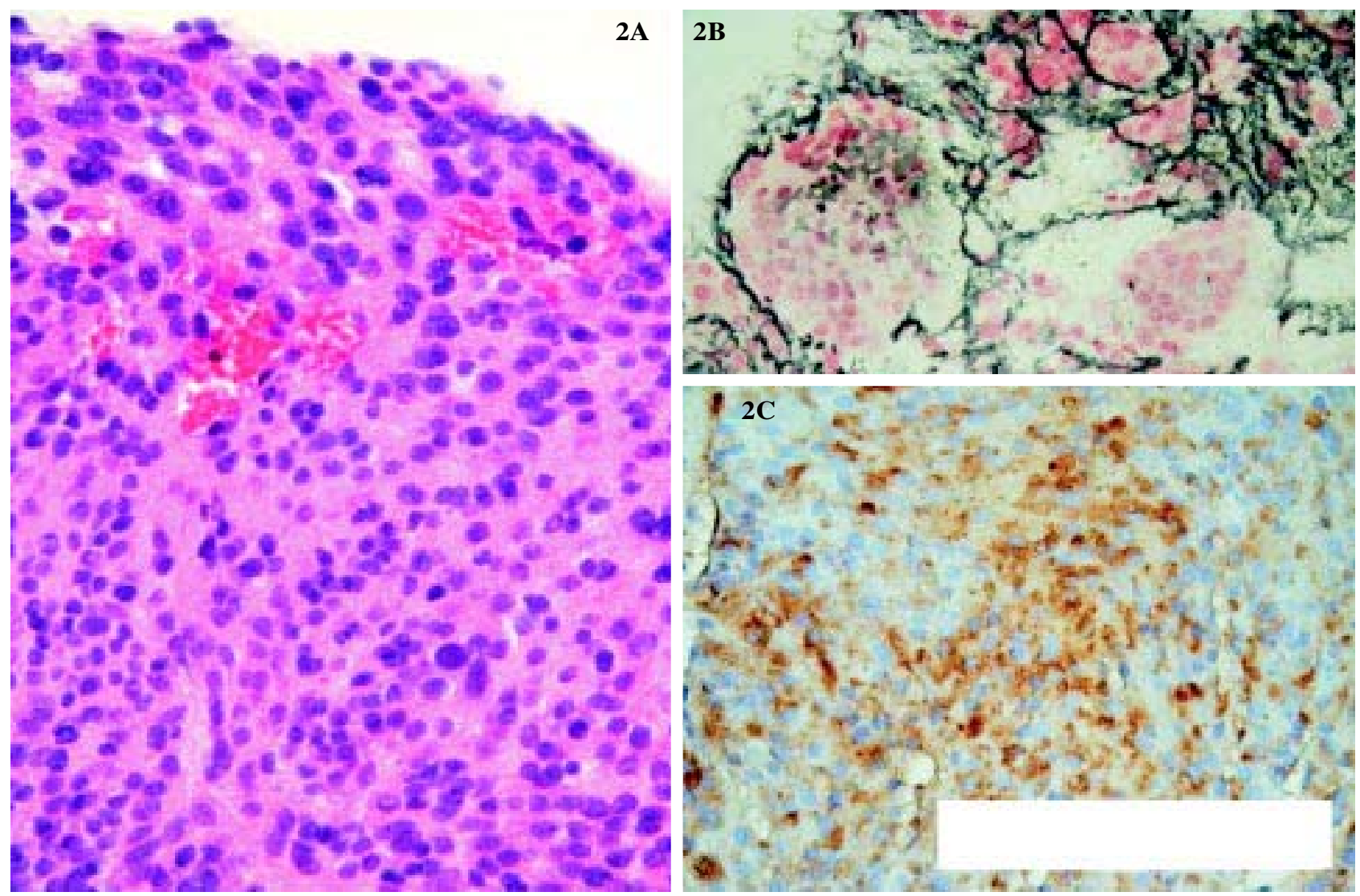

Figure 2. Histology and immunohistochemistry of liver biopsy. 2A. Organoid proliferation of epitheloid cells with prominent vascular component. Tumour cell nuclei variable in size and mitotic figures are identified (H\&E 400X). 2B. Reticulin stain highlights lobular growth pattern (Reticulin Stain 250X). 2C. Immunohistochemistry for Chromogranin A demonstrates diffuse cytoplasmic staining in the tumour cells (Chromogranin A 400X).

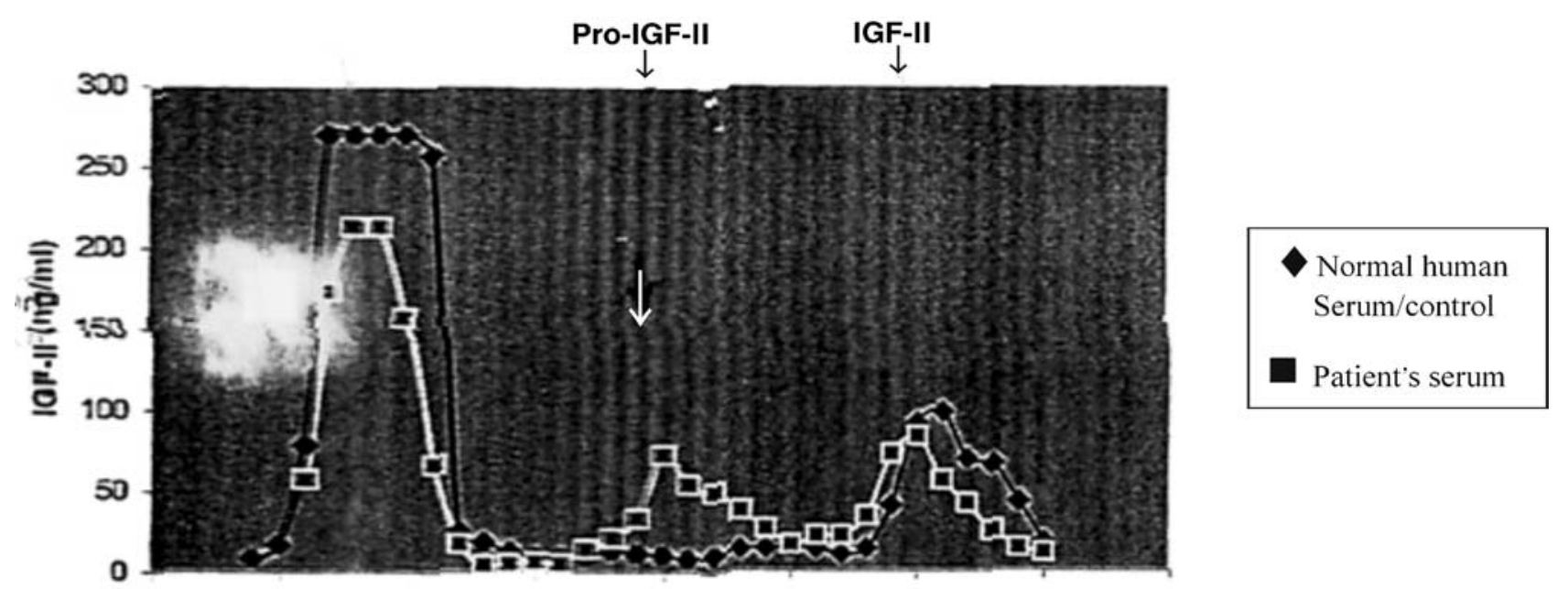

Figure 3. IGF-II size exclusion acid chromatography. Pro-IGF-II and IGF-II levels in patient's serum compared to normal human serum. 
quent control of the hypoglycaemia and improvement in all clinical and biochemical parameters. However, the patient developed pain and loss of power in the left lower limb, and an MR imaging of the spine revealed tumour impingement at the level of L2. Focal radiotherapy (20 Gy over 5 days) was administered with substantial improvement of the symptoms and overall mobility. The patient was discharged on prednisolone $30 \mathrm{mg}$ daily orally, GH $1.3 \mathrm{mg}$ daily subcutaneously and oral opiates. However, three weeks later she presented with pyrexia and further episodes of hypoglycaemia, which responded to intravenous dextrose and higher doses of prednisolone and GH. Unfortunately the patient deceased two weeks following her latest admission; an autopsy was not performed.

\section{METHODS}

Plasma glucose was measured by the glucose oxidase method. Plasma insulin and C-peptide were measured using specific radioimmunoassays. Serum samples for measurement of IGF-1, IGF-II, IGF binding protein (IGFBP-3) and pro-IGF-II were separated immediately and stored at $-40^{\circ} \mathrm{C}$ until analysed as previously described ${ }^{4}$. The results of acid chromatography of Pro-IGF II and IGF II are shown in Figure 3.

\section{DISCUSSION}

This case report illustrates the clinical presentation, underlying pathology and response to treatment in a patient with non-islet cell tumour hypoglycaemia (NICTH). This syndrome has received close investigative attention in recent years, and the diagnosis is suspected when persistent hypoglycaemia, suppressed serum insulin, C-peptide, GH and IGF-1 levels, but apparently normal, or even elevated, serum levels of immunoreactive IGF-II ${ }^{2,5}$ are present. Various tumour types have been associated with NICTH, including adenocarcinomas, thoracic or retroperitoneal sarcomas and mesenchymal cell tumours, hepatomas, carcinoids as well as tumours of unknown origin ${ }^{2}$. Such tumours overexpress the IGF-II gene and secrete an abnormal form of IGF-II which is incompletely sequestered in high molecular weight IGF binding protein (IGFBP) complexes, capable of exerting potent insulin-like activity leading to severe hypoglycemia ${ }^{1,3,5}$. The great majority of patients are elderly and the most effective treatment is surgical debulking; however, this is often difficult to achieve due to the diffuse infiltration of many of these tumours at the time of presentation and the advanced age or poor condition of the patients ${ }^{2}$. Therefore, medical treatment with glucagon, GH, glucocorticoids and long-acting somatostatin analogues have been used in order to obtain symptomatic control ${ }^{2,4,6}$.

Our patient presented to her local hospital with a disseminated large tumour and symptoms that, although non-specific, could have been attributed to tumour related hypoglycaemia. It was only after successive low glucose levels were recorded that the correct diagnosis was made. Although the exact nature of the tumour was not known, there was evidence of a mesenchymal origin of the tumour, a well-known cause of NICTH. In addition, the initial favourable systemic response to chemotherapy with a substantial reduction of the tumour mass is consistent with the origin of these tumour and the associated hypoglycaemia? It has recently been shown that the great majority of such tumours express IGF-II protein and mRNA but few patients have associated hypoglycaemia. It seems that tumours greater than $9 \mathrm{~cm}$ are positive for IGF-II mRNA and may thus be more commonly associated with clinically significant hypoglycaemia ${ }^{7}$. Therefore, an attempt to reduce the tumour mass either surgically or medically should always be made.

Non-islet cell tumour-associated hypoglycaemia is caused by the production of pro-IGFII, which acts on insulin receptors ${ }^{3,5}$. Tumour-derived IGF-II molecules represent truncated forms of pro-IGF-II with molecular weights ranging from $10-20 \mathrm{kD}$, instead of the fully processed $7.4 \mathrm{kD}$ peptide ${ }^{8}$. In normal human serum, $70-80 \%$ of IGF-II is associated with a ternary $150 \mathrm{kD}$ IGFBP complex, consisting of IGF-II, IGFBP-3 and an acid labile subunit (ALS), while $20-30 \%$ is bound to a binary complex of less than $60 \mathrm{kD}$ consisting of IGF-II and IGFBP-3, and less than $2 \%$ is present in the free form ${ }^{1,7,8}$. In NICTH, IGFBP-3 and ALS production is decreased and the ability of the binary complex to form the more stable ternary complex is impaired and thus tumour derived IGF-II appears as binary IGF-IGFBP complexes which has a greatly increased turnover compared with the ternary $150-\mathrm{kDa}^{1}$. Although circulating levels of IGF-II are usually normal, pro-IGF-II interacts with the insulin and IGF-1 receptor and inhibits anterior pituitary GH secretion, which in turn leads to a decreased serum IGF-I con- 
centration $^{3,5}$. The low GH levels also result in a reduction in IGFBP-3 contributing to greater bioavailability of pro-IGF-II ${ }^{4,8}$.

Treatment of such tumours traditionally involves the administration of GH and/or glucocorticoids ${ }^{2}$. GH is thought to exert its beneficial effect by stimulating gluconeogenesis and hepatic glycogenolysis and by increasing IGFBP-3 production and redistribution of serum IGFBP-3 from binary to ternary form, potentially reducing the bioavailability of pro-IGF-II ${ }^{4,6}$. However, this GH effect is induced only at supra-physiological GH doses; with lower GH doses much of the abnormal IGF-II still remains unsequestered and therefore can interact with both the insulin and IGF receptors ${ }^{2,6}$. Prednisolone, at daily doses of $30 \mathrm{mg}$ or more, alleviates hypoglycaemia by direct stimulation of gluconeogenesis and glycogenolysis and may also suppress tumour production and clearance of pro-IGF$\mathrm{II}^{2}$. A significant fall in circulating pro-IGF-II is accompanied by a rise in serum ALS and redistribution of IGFBP-3 from binary to ternary forms ${ }^{8}$. It is therefore probable that although both treatments are similarly effective in relieving hypoglycaemia, glucocorticoid therapy may be of greater long-term benefit through pro-IGF-II suppression and the postulated mechanisms may explain the occasional failures of $\mathrm{GH}$ therapy when administered alone ${ }^{2,6}$. Although these tumours may exhibit somatostatin receptors, therapy with the long-acting somatostatin analogue octreotide has not been effective in relieving hypoglycaemia when used in individual cases $^{4,6}$.

Patients with extensive tumour load and symptoms of autonomic hyperactivity or neuroglycopaenia should always be investigated for NICTH. A combination of GH and prednisolone has proven to be the most effective therapy in alleviating the otherwise intractable hypoglycaemia associated with such tumours and may provide symptomatic palliation to patients.

\section{REFERENCES}

1. Daughaday WH, Trivedi B, Baxter RC, 1993 Serum 'big' insulin-like growth factor II (IGF II) from patients with tumour hypoglycaemia lacks normal E-domain O-linked glycosylation, a possible determinant of normal peptide processing. Proc Nat Acad Scien 90: 5823-5827.

2. Teale JD, Marks V, 1998 Glucocorticoid therapy suppresses abnormal secretion of big IGF-II by non-islet cell tumours inducing hypoglycaemia (NICTH). Clin Enodcrinol 49: 491-498.

3. Marks V, Teale JD, 1993 Hypoglycaemia in the adult. Baillieres Clin Endocrinol Metab 7:705-29.

4. Drake WM, Miraki F, Siddiqi A, et al, 1998 Dose-related effects of growth hormone on IGF-1 and IGF-binding protein-3 levels in non-islet cell tumour hypoglycaemia. Eur J Endocrinol 139: 532-536.

5. Marks V, 1992 Recognition and differential diagnosis of spontaneous hypoglycaemia. Clin Endocrinol 37: 309-16.

6. Perros P, Simpson J, Innes JA, Teale JD, McKnight JA, 1996 Non-islet cells tumour associated hypoglycaemia: 111In-octreotide imaging and efficacy of octreotide, growth hormone and glucocorticosteroids. Clin Endocrinol 44: 727-731.

7. Lloyd RV, Erickson LA, Nascimento AG, Kloppel G, 1999 Neoplasms causing nonhyperinsulinaemic hypoglycaemia. Endocr Pathol 10: 291-297.

8. Hoekman K, von Doorn J, Gloudemans T, Maassen JA, Schuller AGP, Pinedo HM, 1999 Hypoglycaemia associated with the production of insulin-like growth factor II and insulin-like growth factor binding protein 6 by a haemaniopericytoma. Clin Endocrinol 51: 247-253. 